\title{
Características agronômicas produtivas, qualidade e custo de produção de forragem em pastagem de azevém (Lolium multiflorum Lam) fertilizada com dois tipos de adubo
}

\author{
Production, quality and the production cost of forage of \\ ryegrass (Lolium multiflorum Lam) fertilized \\ with two types of fertilizer
}

\author{
Dari Celestino Alves Filho ${ }^{1}$ Mikael Neumann ${ }^{2}$ João Restle ${ }^{3}$ \\ Alexandre Nunes Motta de Souza ${ }^{4}$ Luis Antero de Oliveira Peixoto ${ }^{4}$
}

\section{RESUMO}

Um experimento foi conduzido, com o objetivo de avaliar o comportamento produtivo e qualitativo, bem como, o custo de produção de forragem da pastagem de azevém comum, em pastejo contínuo, fertilizada com dois tipos de adubos: Organo-mineral (AOM) e Químico (AQ). O estabelecimento da pastagem foi em 24/04/1999, com semeadura a lanço e o nivel de adubação, em cobertura, foi de $300 \mathrm{~kg}$ $\mathrm{ha}^{-1}$ do AOM na fórmula 06-08-08 ou do AO na fórmula 10-18-20. Não houve interação significativa entre os fertilizantes e periodo de avaliação para as variáveis estudadas. A fonte de nutrientes, para os valores médios, não afetou significativamente o teor de matéria seca (MS) no resíduo (22,6 vs 22,2\%), a taxa de acumulação diária (72,3 vs $63,3 \mathrm{~kg} \mathrm{ha} \mathrm{h}^{-1}$ de MS), a produção total de forragem $(7.518 \mathrm{vs} 6.801 \mathrm{~kg} \mathrm{ha}$ ${ }^{1}$ de MS), o teor de proteina bruta (12,8 vs 12,7\%), a fibra em detergente neutro (57,4 vs 57,4\%) e a fibra em detergente ácido (31,0 vs 32,3\%), respectivamente, para o AOM e AQ. O custo total da pastagem foi de 225,90 e 253,50 R\$ ha ${ }^{-1}$, e a fonte de nutrientes representou 37,6 e 44,4\%, respectivamente, para o AOM e AQ. Para o custo de forragem produzida, os valores foram de 0,030 e 0,037 $R \$ \mathrm{~kg}^{-1}$ de MS para a pastagem fertilizada com AOM e $A Q$, respectivamente.

Palavras-chave: adubo organo - mineral, economicidade, potencial de produção.

\section{ABSTRACT}

One experiment was conducted, with the purpose to evaluate the production, quality and the production cost of forage of ryegrass, in continuous grazing, fertilized with two types of fertilizer: Organic-mineral (FOM) and chemical (FC) applied as top dressing. The pasture was implanted in 04/24/1999, with top-seeding, and the level of fertilizer was $300 \mathrm{~kg} \mathrm{ha}^{-1}$ of FOM formula 06-08-08 or FC formula 10-18-20. No significant interaction between fertilizer and evaluation period was observed for the variables studied. The fertilizer sources did not affect the percentage of dry matter (DM) in the residue (22.6 vs $22.2 \%)$, the accumulation rate of dry matter (72.3 vs $63.2 \mathrm{~kg} \mathrm{ha}^{-1}$ of DM), the total forage production (7518 vs $6801 \mathrm{~kg} \mathrm{ha}^{-1}$ of DM), the percentage of crude protein (12.8 vs 12.7\%), the neutral detergent fiber (57.4 vs 57.4\%) and acid detergent fiber (31.0 vs $32.3 \%$ ), for FOM and FC, respectively. The total cost of the pasture was of 225.90 and $253.50 \mathrm{R} \$ \mathrm{ha}^{-1}$, where the fertilizer represented 37.6 and $44.4 \%$, respectively, for FOM and FC. The production cost of the pasture DM was 0.030 and $0.037 \mathrm{RS} \mathrm{kg}^{-1}$, for FOM and FC, respectively.

Key words: organic-mineral fertilizer, cost, yield potential.

\footnotetext{
${ }^{1}$ Engenheiro Agrônomo, MSc., Professor Assistente do Departamento de Zootecnia da UFSM, Campus Camobi Santa Maria, RS, CEP 97105-900. E mail: dcafilho@ccr.ufsm.br Autor para correspondência.

${ }^{2}$ Engenheiro Agrônomo, MSc., Departamento de Zootecnia da UFSM. E mail: mikaelneumann@hotmail.com

${ }^{3}$ Engenheiro Agrônomo, PhD., Pesquisador do CNPq, Professor Titular do Departamento de Zootecnia da UFSM. E mail: jorestle@ccr.ufsm.br

${ }^{4}$ Bolsista do CNPq, Aluno de graduação do Curso de Medicina Veterinária da UFSM.
} 


\section{INTRODUÇÃO}

O Estado do Rio Grande do Sul possui alto grau de desenvolvimento tecnológico no setor da pecuária de corte no Brasil, porém, não se tem obtido rendimentos satisfatórios. Segundo ROSO et al. (2000a), a base da alimentação da pecuária de corte no Rio Grande do Sul é o campo nativo, composto basicamente por espécies de crescimento estival, com concentração da produção de forragem no verão, paralisação do crescimento e decréscimo da qualidade da forragem no outono-inverno, constituindose num dos principais entraves para a elevação dos índices produtivos do rebanho bovino.

Os índices de produtividade das pastagens cultivadas são influenciados pelas condições edafo-climáticas. Sabe-se que, além do potencial genético da cultura e do meio ambiente, a produção é influenciada, entre outros fatores, por qualidade da semente, época de semeadura, população de plantas, preparo e correção do solo, controle de plantas daninhas, pragas e doenças, e o grau de fertilização dos solos (MÜHLBACH, 1998). Atualmente, a pastagem cultivada de gramíneas anuais de estação fria é uma alternativa viável à alimentação de bovinos na fase de recria e terminação, por ser um alimento de alta qualidade e suprir o déficit alimentar deste período (ROSO et al., 2000b). Segundo PIMENTEL et al. (1998), a espécie forrageira deve expressar elevada produção de massa por unidade de área e ser um alimento de alta qualidade para os animais. No entanto, ressalta-se que a relação produção:qualidade da forragem depende diretamente das características de fertilidade do solo cultivado.

No processo de implantação e condução de pastagens cultivadas de inverno, os fertilizantes representam o maior custo, verificando-se que normalmente os produtores de carne tem optado pela redução proporcional destes, o que condiciona a um decréscimo acentuado na produção e na qualidade da forragem, além da quebra de resistência à seca, às doenças e pragas da mesma. LOPES (1989) afirma que a redução da dose do fertilizante aplicado contribui para a descapitalização do produtor, visto que o imposto sobre a terra, as taxas de juros, os custos das sementes e dos defensivos, bem como os custos fixos do sistema de produção, serão mantidos.

O fertilizante organo-mineral é constituído na forma de grânulos, pela mistura de linhito (carvão fóssil secundário composto de matéria lenhosa e restos vegetais macerados) contendo $25 \%$ de matéria orgânica, calcário dolomítico (neutralizante de $\mathrm{pH}=5,5$ ) e fertilizantes minerais, entre eles, fosfato monoamônico (MAP), fosfato diamônico (DAP), superfosfato simples e superfosfato triplo, além do sulfato de amônio e cloreto de potássio. O componente linhito, é um material cuja degradação encontra-se entre a turfa e o antracito betuminoso, o que indica, que os fertilizantes organo-minerais desempenham 3 funções diferentes no solo: fertilizante, corretiva e melhoradora das propriedades do solo (KIEHL, 1985).

O fertilizante organo-mineral comparado ao fertilizante mineral, apresenta um custo relativamente inferior, porém, seu potencial químico reativo é menor, mas sua solubilização é gradativa no decorrer do período de desenvolvimento da cultura, quando a eficiência agronômica pode se tornar maior (KIEHL, 1985). No panorama de produção de forragem a partir de pastagens cultivadas de inverno, os custos de estabelecimento são elevados e as opções agrícolas com potencial de produção de biomassa dependem diretamente do nível de fertilidade do solo (RESTLE et al., 1999), logo, estes recursos devem ser usados de forma racional, visando aumentar a eficiência de utilização da forragem e tornar os sistemas de produção animal mais produtivos e viáveis economicamente.

O objetivo deste trabalho foi avaliar as características produtivas e qualitativas da forragem e o custo de produção da mesma numa pastagem de azevém fertilizada com adubo organo-mineral ou químico, sob pastejo contínuo.

\section{MATERIALE MÉTODOS}

O experimento foi conduzido nas instalações do Setor de Bovinocultura de Corte do Departamento de Zootecnia da Universidade Federal de Santa Maria, situada na Depressão Central do Rio Grande do Sul, numa altitude de $95 \mathrm{~m}$. Cartograficamente se localiza a $29^{\circ} 43^{\prime}$ de latitude Sul e $53^{\circ} 42^{\prime}$ de longitude Oeste. O solo pertence à unidade de mapeamento São Pedro, classificado como Argiloso Vermelho Distrófico Arênico e o clima da região é Cfa (Subtropical úmido), conforme a classificação de Köppen, com precipitação média anual de $1.769 \mathrm{~mm}$, temperatura média anual de $19,2^{\circ} \mathrm{C}$, com média mínima de $9,3^{\circ} \mathrm{C}$ em julho e média máxima de $24,7{ }^{\circ} \mathrm{C}$ em janeiro, insolação de 2.212 horas anuais e umidade relativa do ar de $82 \%$ (MORENO, 1961).

O período experimental foi de 24/04 a 30/10/99 e a área total utilizada no experimento foi de $16 \mathrm{ha}$, sub-dividida em quatro áreas de cultivo de quatro hectares cada. Os tratamentos foram: $\mathrm{T}_{\mathrm{AOM}}$ - pastagem fertilizada com adubo organo-mineral (AOM) na formulação 06-08-08 e $\mathrm{T}_{\mathrm{AQ}}-$ pastagem fertilizada adubo com químico (AQ) na formulação 10-18-20.

O solo da área experimental, em 15 de abril de 1999 apresentou as seguintes características químicas: $\mathrm{pH}$ água: 4,8; P: 19,3mg L-1 $\mathrm{K}: 79,0 \mathrm{mg} \mathrm{L}^{-1}$; MO: 3,1\%; Al: 2,2 $\mathrm{cmol}_{\mathrm{c}} \mathrm{L}^{-1}$; Ca: 7,9 $\mathrm{cmol}_{\mathrm{c}} \mathrm{L}^{-1}$; Mg: 4,0 $\mathrm{cmol}_{\mathrm{c}} \mathrm{L}^{-1}$; CTC efetiva: $14,2 \mathrm{cmol} \mathrm{L}^{-1}$; e Saturação de bases: $63 \%$. A pastagem de azevém (Kolium multiflorum Lam.) foi implantada nos dias 24 e 25 de abril de 1999, em sistema de plantio convencional 
com semeadura à lanço, na resteva de lavouras de sorgo (Sorghum bicolor L. Moench) para silagem, utilizando-se uma densidade de $60 \mathrm{~kg} \mathrm{ha}^{-1}$ de sementes de azevém. A adubação foi realizada em cobertura, 50 dias após o plantio $(11 / 07)$, na dosagem de $300 \mathrm{~kg} \mathrm{ha}^{-1}$, para ambos os tratamentos, enquanto a adubação nitrogenada foi realizada na fase de perfilhamento da pastagem, no dia 18/08, na dosagem de $45 \mathrm{~kg} \mathrm{ha}^{-1} \mathrm{de} \mathrm{N}$ na forma de uréia. Os animais entraram na pastagem 100 dias após o seu estabelecimento e o período total de utilização foi de 86 dias. A quantidade de adubo aplicado foi equivalente em produto comercial, conforme recomendações da empresa fabricante do adubo organo-mineral.

Os animais foram mantidos na pastagem em sistema de pastejo contínuo com lotação variável, com uma massa de forragem média de $1.995 \mathrm{~kg}$ de MS ha-1. Os animais utilizados foram novilhas e vacas da raça Charolês, Nelore e suas cruzas.

A avaliação da disponibilidade de MS da forragem e da altura da pastagem foi realizada a cada 28 dias aproximadamente, durante o período de utilização da pastagem $(05 / 08,31 / 08,02 / 10$ e 30/10/99), pela técnica de dupla amostragem (GARDNER, 1986). Em cada unidade experimental, seis amostras foram cortadas rente ao solo $\left(0,25 \mathrm{~m}^{2}\right.$.amostra $\left.{ }^{-1}\right)$ e 24 foram avaliadas visualmente. Estas amostras de forragem foram pesadas individualmente e homogeneizadas e, em seguida, uma sub-amostra composta por período foi utilizada para determinação do teor de matéria seca (MS) em estufa de ar forçado a $60^{\circ} \mathrm{C}$, por 72 horas, sendo seqüencialmente moída em moinho tipo Willey, com peneira de malha $1 \mathrm{~mm}$. Nas análises bromatológicas, foi determinado o nitrogênio total pelo método micro Kjeldahl, sendo, posteriormente, multiplicado pelo fator 6,25 para obtenção da proteína bruta (PB), segundo AOAC (1984). A fibra em detergente neutro (FDN) foi determinada conforme GOERING \& VAN SOEST (1970) e a fibra em detergente ácido (FDA) conforme AOAC (1990).

A taxa de acumulação foi avaliada em períodos de aproximadamente 28 dias, utilizando-se três gaiolas de exclusão ao pastejo por unidade experimental, adotandose o método do triplo emparelhamento (MORAES et al., 1990). A produção total de MS foi obtida pelo somatório das produções dos períodos de avaliação (taxa de acumulação $\mathrm{x} \mathrm{n}^{\circ}$ de dias) mais o resíduo inicial, no momento da entrada dos animais na pastagem.

O delineamento experimental foi de blocos ao acaso, composto por dois tratamentos com duas repetições, nos quais cada repetição constou de uma área de cultivo de quatro hectares da pastagem. Os dados dos parâmetros avaliados foram submetidos à análise de variância, sendo usado o seguinte modelo matemático: $\mathrm{Y}_{\mathrm{ijk}}=\mu+\mathrm{FN}+\mathrm{B}+$ $\left(\mathrm{FN}^{*} \mathrm{~B}\right)_{\mathrm{ij}}+\mathrm{P}_{\mathrm{k}}+(\mathrm{FN} * \mathrm{P})_{\mathrm{ik}}+\mathrm{E}_{\mathrm{ijk}}$, onde: $\mathrm{Y}_{\mathrm{ijk}}=$ variávéis dependentes; $\mu=$ Média de todas as observações; $\mathrm{FN}_{\mathrm{i}}=$
Efeito da fonte de nutrientes de índice i, sendo 1 (adubo organo-mineral) e 2 (adubo químico); $\mathrm{B}=$ Efeito do bloco de índice $\mathrm{j} ;(\mathrm{FN} * \mathrm{~B})=$ Efeito da interaçãjo entre tratamento de índice i e bloco de índice $\mathrm{j}$ (Erro a); $\mathrm{P}=$ Efeito do período de avaliação de índice $\mathrm{k}$, sendo 1 (primeiro período), 2 (segundo período) e 3 (terceiro período); $(\mathrm{FN} * \mathrm{P})=$ Efeito da interação entre tratamento de índice i e período de índice $\mathrm{k}$; e $\mathrm{E}_{\mathrm{ijkl}}=$ Efeito do erro aleatório associado a cada observação (Erro b).

Os dados de cada parâmetro avaliado foram analisados por análise da variância por meio do programa estatístico SAS (1993). Foram realizadas as comparações das médias analisadas pelo teste $\mathrm{F}$ e teste Tukey em nível de $5 \%$ de probabilidade de erro.

\section{RESULTADOS E DISCUSSÃO}

Não houve interação significativa entre tipo de adubo (Adubo organo-mineral e adubo químico) e período de avaliação para os parâmetros qualitativos da pastagem: teores de matéria seca, de fibra em detergente neutro, de fibra em detergente ácido, de hemicelulose, de celulose e de lignina, bem como para os parâmetros quantitativos: altura da pastagem, taxa de acumulação diária e produção de forragem.

Os resultados do resíduo inicial, taxa de acumulação média diária, produção de forragem e carga animal são apresentados na tabela 1 . A taxa de acumulação média diária de matéria seca não foi afetada pela fonte de nutrientes, verificando-se valores de 72,3 e $63,3 \mathrm{~kg} \mathrm{ha}^{-1} \mathrm{de}$ MS para o adubo organo-mineral e adubo químico, respectivamente. No entanto, numericamente os valores médios da taxa de crescimento da pastagem de azevém, quando fertilizada com adubo organo-mineral, apresentou uma superioridade de $14,3 \%$ em relação a fertilizada com adubo químico.

Com relação aos períodos de avaliação, verificase que o ponto máximo de crescimento diário da pastagem de azevém ocorreu no segundo período (01/09 a 02/10), sendo de 123,6 e $92,6 \mathrm{~kg} \mathrm{ha}^{-1} \mathrm{de}$ MS, para o adubo organomineral e adubo químico, respectivamente, o que caracterizou a pastagem como de ciclo primaveril. A estabilidade de produção de forragem (Tabela 1) é uma característica tão importante, ou em alguns casos, até mais importante do que a produção total de MS de uma espécie, sendo o ideal uma pastagem que tivesse sua taxa de acumulação em equilíbrio constante com a carga animal à qual é submetida, o que não acontece por questões, entre outras, climáticas, fenológicas e de manejo, entre outras.

A produção total de matéria seca, obtida durante o período da semeadura (25/04) até o final da utilização da pastagem (30/10), foi similar para o adubo organo-mineral (7.518kg ha-1 de MS) e para adubo químico $\left(6.801 \mathrm{~kg} \mathrm{ha}^{-1} \mathrm{de}\right.$ 
Tabela 1 - Resíduo inicial, taxa de acumulação média diária, produção e distribuição da produção de forragem e carga animal média da pastagem de azevém, submetida ao pastejo contínuo, fertilizada com adubo organo-mineral (AOM) e adubo químico (AQ) nos diferentes períodos de avaliação.

\begin{tabular}{|c|c|c|c|c|c|}
\hline \multirow[b]{2}{*}{ Fertilizantes } & \multirow{2}{*}{$\begin{array}{c}\text { Resíduo } \\
\text { Inicial } \\
\left(\mathrm{kg} \mathrm{ha}^{-1} \mathrm{MS}\right)\end{array}$} & \multicolumn{3}{|c|}{ Períodos de avaliação da pastagem } & \multirow[b]{2}{*}{ Média/Total } \\
\hline & & $05 / 08$ a $31 / 08$ & $01 / 09$ a $02 / 10$ & $03 / 10$ a $30 / 10$ & \\
\hline & \multicolumn{5}{|c|}{ - - - - - - Taxa de acumulação diária $\left(\mathrm{kg} \mathrm{ha}^{-1} \mathrm{de} \mathrm{MS}\right)$ - - - - - - - } \\
\hline $\mathrm{AOM}$ & & 40,2 & 123,6 & 53,2 & $72,3 \mathrm{~A}$ \\
\hline AQ & & 40,0 & 92,6 & 57,3 & $63,3 \mathrm{~A}$ \\
\hline \multirow[t]{2}{*}{ Média } & & $40,1 \mathrm{~b}$ & $108,1 \mathrm{a}$ & $55,2 \mathrm{~b}$ & \\
\hline & \multicolumn{5}{|c|}{ - - Produção de forragem $\left(\mathrm{kg} \mathrm{ha}^{-1}\right.$ de MS $)$} \\
\hline $\mathrm{AOM}$ & 990 & 1.085 & 3.954 & 1.489 & $7.518 \mathrm{~A}$ \\
\hline AQ & 1.157 & 1.079 & 2.961 & 1.604 & $6.801 \mathrm{~A}$ \\
\hline \multirow[t]{2}{*}{ Média } & $1.074 \mathrm{~b}$ & $1.082 \mathrm{~b}$ & $3.458 \mathrm{a}$ & $1.546 \mathrm{~b}$ & \\
\hline & \multicolumn{5}{|c|}{ - - - - - - - - Distribuição da produção de forragem (\%) - - - - - - - } \\
\hline $\mathrm{AOM}$ & 13,2 & 14,4 & 52,6 & 19,8 & 100 \\
\hline AQ & 17,0 & 15,9 & 43,6 & 23,6 & 100 \\
\hline \multirow[t]{2}{*}{ Média } & 15,1 & 15,1 & 48,1 & 21,7 & \\
\hline & \multicolumn{5}{|c|}{ 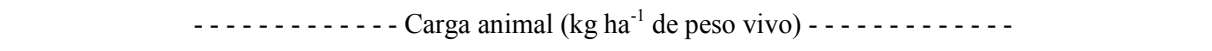 } \\
\hline Média & - & 1.369 & 1.429 & 1.513 & 1.437 \\
\hline
\end{tabular}

A,B - Médias na coluna com letras maiúsculas diferentes diferem entre si pelo teste $\mathrm{F}$ em nível de $5 \%$ de probabilidade de erro.

a,b - Médias na linha com letras minúsculas diferentes diferem entre si pelo teste Tukey em nível de $5 \%$ de probabilidade de erro.

MS), entretanto, numericamente, o adubo organo-mineral propiciou aumento de $10,5 \%$ produção de forragem. Analisando o potencial produtivo de forrageiras anuais de estação fria no período de 1994 a 1996, GOMES \& REIS (1997) obtiveram produções médias de $4.398 \mathrm{~kg} \mathrm{ha}^{-1}$ de MS. Segundo KIEHL (1985), a composição do fertilizante organo-mineral apresenta o componente nitrogênio na forma orgânica, a qual não é sujeita a perdas intensas por lixiviação, sendo que esse componente é liberado aos poucos, conforme a decomposição do material. Garante também suprimento mais uniforme e prolongado dos nutrientes às plantas, o que condicionou no presente estudo, numericamente a maior taxa de acumulação diária, com conseqüente incremento na produção total de forragem. Segundo LUPATINI (1996), o nitrogênio é o principal nutriente responsável pela produção de matéria seca da pastagem e estabilidade dos teores de proteína bruta e digestibilidade da massa de forragem das pastagens cultivadas hibernais sob pastejo contínuo.

A pastagem de azevém apresentou maior desenvolvimento durante a primavera (setembro e outubro), concentrando 72,4 e $67,1 \%$ da sua produção total de massa seca neste período, contra 27,6 e $32,9 \%$ no período de outono-inverno (maio, junho, julho e agosto), para o adubo organo-mineral e adubo químico (Tabela 1), respectivamente, comprovando a importância da estabilidade de produção da pastagem para o planejamento forrageiro no manejo alimentar dos sistemas de produção animal, visto que as pastagens de inverno são usadas no sul do país para suprir o déficit de forragem (vazio forrageiro) durante este período do ano (RESTLE et al., 1997), no entanto ressalta-se que estes recursos devem ser usados de maneira racional e mais eficiente possível, para viabilizar economicamente a atividade. GOMES \& REIS (1997) observaram uma concentração de produção de forragem relativa para o azevém de $56 \%$ no período da primavera, $30 \%$ no inverno e $14 \%$ no outono. Esta diferença na distribuição estacional é verificada em função de particularidades às condições climáticas, conforme ano agrícola e épocas de semeadura .

Na tabela 2, são apresentadas as características qualitativas da massa de forragem disponível da pastagem de azevém. Verifica-se que o teor médio de matéria seca não foi afetado pela fonte de nutrientes usada, apresentando porcentagens de 22,6 e 22,2\% para o adubo organo-mineral e adubo químico, respectivamente. Ao analisar os teores de matéria seca da massa de forragem disponível durante os períodos de utilização da pastagem (05/08, 31/08, 02/10 e 30/ 10), todas as médias diferiram estatisticamente entre si, constatando-se o aumento dos teores de matéria seca em função do avanço do processo de maturação fisiológica das plantas, independente do tipo de adubo utilizado.

Analisando os valores médios da tabela 2, a altura da pastagem fertilizada com adubo químico foi 
Tabela 2 - Altura da pastagem e teores de matéria seca (MS), de proteína bruta (PB), de fibra em detergente neutro (FDN) e de fibra em detergente ácido (FDA) da massa de forragem disponível da pastagem de azevém, submetida ao pastejo contínuo, fertilizada com adubo organo-mineral (AOM) e adubo químico (AQ) nos diferentes períodos de avaliação.

\begin{tabular}{|c|c|c|c|c|c|}
\hline \multirow[t]{2}{*}{ Fertilizantes } & \multicolumn{4}{|c|}{ Datas de avaliação da pastagem } & \multirow[t]{2}{*}{ Média } \\
\hline & $05 / 08$ & $31 / 08$ & $02 / 10$ & $30 / 10$ & \\
\hline & \multicolumn{5}{|c|}{ 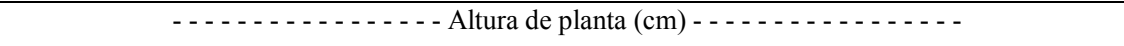 } \\
\hline $\mathrm{AOM}$ & 15,0 & 21,3 & 20,2 & 17,7 & $18,5 \mathrm{~B}$ \\
\hline AQ & 15,0 & 27,8 & 21,3 & 21,5 & $21,4 \mathrm{~A}$ \\
\hline \multirow[t]{2}{*}{ Média } & $15,0 \mathrm{~b}$ & $24,5 \mathrm{a}$ & $20,7 \mathrm{ab}$ & $19,6 \mathrm{ab}$ & \\
\hline & \multicolumn{5}{|c|}{ 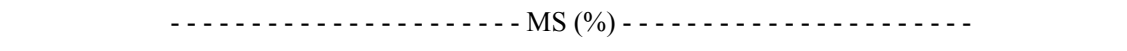 } \\
\hline $\mathrm{AOM}$ & 18,9 & 17,2 & 24,0 & 30,3 & $22,6 \mathrm{~A}$ \\
\hline AQ & 18,9 & 16,6 & 23,6 & 29,5 & $22,2 \mathrm{~A}$ \\
\hline \multirow[t]{2}{*}{ Média } & $18,9 \mathrm{c}$ & $16,9 \mathrm{~d}$ & $23,8 \mathrm{~b}$ & 29,9 a & \\
\hline & \multicolumn{5}{|c|}{ 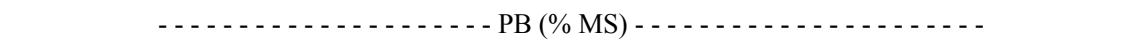 } \\
\hline $\mathrm{AOM}$ & 11,8 & 20,8 & 10,2 & 9,1 & $12,8 \mathrm{~A}$ \\
\hline AQ & 14,0 & 18,9 & 9,1 & 8,9 & $12,7 \mathrm{~A}$ \\
\hline \multirow[t]{2}{*}{ Média } & $12,9 \mathrm{~b}$ & $19,9 \mathrm{a}$ & $9,7 \mathrm{bc}$ & $8,7 \mathrm{c}$ & \\
\hline & \multicolumn{5}{|c|}{ 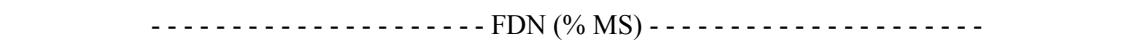 } \\
\hline $\mathrm{AOM}$ & 51,6 & 55,2 & 57,5 & 65,2 & $57,4 \mathrm{~A}$ \\
\hline AQ & 55,0 & 56,6 & 55,0 & 63,0 & $57,4 \mathrm{~A}$ \\
\hline \multirow[t]{2}{*}{ Média } & $53,3 \mathrm{~b}$ & $55,9 \mathrm{~b}$ & $56,2 \mathrm{~b}$ & $64,10 \mathrm{a}$ & \\
\hline & \multicolumn{5}{|c|}{ - } \\
\hline AOM & 28,8 & 29,2 & 31,4 & 34,5 & $31,0 \mathrm{~A}$ \\
\hline AQ & 32,4 & 29,3 & 30,5 & 36,7 & $32,3 \mathrm{~A}$ \\
\hline Média & $30,6 \mathrm{ab}$ & $29,3 \mathrm{~b}$ & $30,9 a b$ & $35,6 \mathrm{a}$ & \\
\hline
\end{tabular}

A,B - Médias na coluna com letras maiúsculas diferentes diferem entre si pelo teste $\mathrm{F}$ em nível de $5 \%$ de probabilidade de erro.

a,b,c,d - Médias na linha com letras minúsculas diferentes diferem entre si pelo teste Tukey em nível de $5 \%$ de probabilidade de erro.

superior à fertilizada com adubo organo-mineral $(21,4$ contra e $18,5 \mathrm{~cm}$, respectivamente). Já os valores médios encontrados para os teores de proteína bruta não diferiram com valores de 12,8 e 12,7\%, para o adubo organo-mineral e adubo químico (Tabela 2), respectivamente. Com relação aos períodos de avaliação, os teores de proteína bruta do resíduo da pastagem do segundo período de avaliação foram superiores às demais avaliações, independentemente do tipo de adubo utilizado. Este efeito, em grande parte, ocorreu em função da adubação nitrogenada, em cobertura, realizada no dia 18/08. RESTLE et al. (2000) encontraram valores médios superiores para proteína bruta (22,1 e 22,7\%) para mistura de aveia mais azevém, adubadas com uréia e sulfato de amônio, respectivamente, porém, com nível de nitrogênio em cobertura de $200 \mathrm{~kg} \mathrm{ha}^{-1}$ para ambas as fontes, enquanto no presente trabalho de pesquisa o nível de nitrogênio foi de apenas $45 \mathrm{~kg} \mathrm{ha}^{-1}$. Nas avaliações subseqüentes, os teores de proteína bruta decresceram, decorrentes do baixo nível de adubação nitrogenada, o que refletiu negativamente na duração do ciclo da pastagem, conduzido pelo espessamento das paredes celulares das plantas pelo processo de lignificação, diminuindo consideravelmente a qualidade.

Na média geral, os teores médios de FDN foram de 57,4 e 57,4\% e de FDA de 31,0 e 32,3\%, sendo semelhantes entre si, para a pastagem de azevém fertilizada com adubo organo-mineral e químico, respectivamente (Tabela 2). RESTLE et al. (1997) afirmam que o nível de adubação nitrogenada condiciona e determina a qualidade da forragem produzida. Outro aspecto importante para a manutenção da qualidade da pastagem na fase final de sua utilização relaciona-se à diminuição da área foliar em função do pastejo seletivo por parte dos animais e, segundo RESTLE et al. (2000), pelo decréscimo natural na relação folha:caule (F:C) com a elongação dos primórdios florais, bem como a uma acelerada taxa de acumulação de materiais estruturais. LESAMA (1997) verificou comportamento semelhante para o azevém que apresentou relação $\mathrm{F}: \mathrm{C}$ de 1,19 no mês de agosto, reduzindo drasticamente para 0,53 no mês de outubro, logo, pressupõem-se que, com o decréscimo da relação $F: C$, ocorra uma diminuição da qualidade da pastagem.

Ciência Rural, v. 33, n. 1, jan-fev, 2003. 
Tabela 3 - Custo da pastagem de azevém, submetida ao pastejo contínuo, fertilizada com adubo organo-mineral (AOM) e adubo químico (AQ).

\begin{tabular}{lcc}
\hline \multicolumn{1}{c}{ Componente do Custo } & \multicolumn{2}{c}{ Fonte de nutrientes } \\
\cline { 2 - 3 } & AOM (06-08-08) & AQ (10-18-20) \\
\hline Arrendamento da terra & 30,00 & 30,00 \\
Calagem & 20,00 & 20,00 \\
Mecanização & 36,00 & 36,00 \\
Semente de azevém & 27,00 & 27,00 \\
Adubação de base & 84,90 & 112,50 \\
Uréia & 28,00 & 28,00 \\
TOTAL & 225,90 & 253,50 \\
\hline
\end{tabular}

* - Preços médios referentes ao ano agrícola de 1999.

Esta dinâmica do comportamento qualitativo da pastagem é melhor explicada pelos valores médios encontrados nos constituintes da parede celular da massa de forragem disponível, durante as fases de desenvolvimento do azevém (Tabela 2). Os teores de FDN e FDA mostraram-se favorecidos com o avanço do ciclo da planta do azevém à fase de maturação fisiológica, o que proporcionou um decréscimo acentuado no valor nutritivo e na porcentagem digestível de alimento disponível ao pastejo dos animais, independentemente da fonte de nutrientes testada.

No custo total de produção da pastagem (R\$ ha $^{-1}$ ) (Tabela 3), observaram-se valores de R \$ 225,90 e R \$ 253,50 , para o adubo organo-mineral e adubo químico, no qual a fonte de nutrientes representou 37,6 e $44,4 \%$ do custo total, respectivamente.

$\mathrm{O}$ custo. $\mathrm{kg}^{-1}$ de MS produzida foi de $\mathrm{R} \$ 0,030 \mathrm{e}$ $\mathrm{R} \$ 0,037$, o que representou uma economia média de $\mathrm{R} \$$ 27,60 por hectare, em favor do adubo organo-mineral. Estes resultados econômicos demonstram, que embora não havendo diferença significativa na produção total de MS, o custo total da pastagem ( $\left.\mathrm{R} \$ \mathrm{ha}^{-1}\right)$ e o custo produtivo ( $\mathrm{R} \$ \mathrm{~kg}^{-1}$ de MS) foram, respectivamente, 10,9 e 18,9\% inferiores com a utilização do adubo organo-mineral na fórmula 06-08-08 comparado ao adubo químico na fórmula 10-18-20.

\section{CONCLUSÕES}

A substituição do adubo químico da fórmula 10-18-20, por organo-mineral, da fórmula 06-08-08, não influenciou as características produtivas e qualitativas da pastagem de azevém, sob pastejo contínuo. O adubo organo-mineral é uma alternativa economicamente viável para os sistemas de produção de bovinos a pasto, pois proporcionou reduções de $10,8 \%$ no custo total da forragem produzida ( $\left.\mathrm{R} \$ \mathrm{ha}^{-1}\right)$ e de $18,9 \%$ no custo produtivo da matéria seca $\left(\mathrm{R} \$ \mathrm{~kg}^{-1}\right)$.

\section{REFERÊNCIAS BIBLIOGRÁFICAS}

AOAC - ASSOCIATION OF OFFICIAL ANALYTICAL CHEMISTS. Official methods of analysis. 14.ed. Arlington Virginia, 1984. 1141p.

ASSOCIATION OF OFFICIAL ANALYTICAL CHEMISTS AOAC. Official methods of analysis. 15.ed. Arlington Virginia, 1990. v.1, 1298p.

GARDNER, A.L. Técnicas de pesquisa em pastagens e aplicabilidade de resultados em sistemas de produção. Brasília : IICA/EMPBRAPA-CNPGL, 1986. 197p. (IICA, Série publicações Miscelâneas, 634).

GOERING, H.K.; VAN SOEST, P.J. Forage fiber analysis: apparatus reagents, procedures and some applications. USDA/ARS, Washington: Agricultural Handbook, 1970. n.379.

GOMES, J.F.; REIS, J.C.L. Produção de forrageiras anuais de estação fria no Litoral sul do Rio Grande do Sul. In: REUNIÃO ANUAL DA SOCIEDADE BRASILEIRA DE ZOOTECNIA, 34., 1997, Juiz de Fora. Anais... Juiz de Fora : SBZ, 1997. p.83-85.

KIEHL, E.J. Fertilizantes orgânicos. Piracicaba : Agronômica CERES, 1985. 492p.

LESAMA, M.F. Produção animal em gramíneas de estação fria com fertilização nitrogenada ou associadas com leguminosa, com e sem fertilização nitrogenada. 1997. 129f. Dissertação (Mestrado em Zootecnia) - Curso de Pósgraduação em Zootecnia, Universidade Federal de Santa Maria.

LOPES, A.S. Manual de fertilidade do solo. Trad. e adapt. de Alfreto Scheid Lopes. São Paulo : ANDA/PATAFOS, 1989. 155p.

LUPATINI, G.C. Produção animal em milheto (Pennisetum americanum (L.) Leeke) submetido a níveis de adubação nitrogenada. 1996. 126p. Dissertação (Mestrado em Zootecnia) - Curso de Pós-graduação em Zootecnia, Universidade Federal de Santa Maria.

Ciência Rural, v. 33, n. 1, jan-fev, 2003. 
MORAES, A.; MOOJEN, E.L.; MARASCHIN, G.E. Comparação de métodos de estimativa de taxas de crescimento em uma pastagem submetida a diferentes pressões de pastejo. In: REUNIÃO ANUAL DA SOCIEDADE BRASILEIRA DE ZOOTECNIA, 27., 1990, Campinas, SP. Anais... Piracicaba : FEALQ, 1990. p.332.

MORENO, J.A. Clima do Rio Grande do Sul. Porto Alegre : Secretaria da Agricultura, 1961. 41p.

MÜHLBACH, P.R.F. Uso de silagens na produção animal. In: CICLO DE PALESTRAS EM PRODUÇÃO E MANEJO DE BOVINOS DE CORTE - ULBRA - Universidade Luterana do Brasil, 1998, Canoas, RS. Anais... Canoas : ULBRA, 1998. p.40-53.

PIMENTEL, J.J.O. et al. Efeito da suplementação protéica no valor nutritivo de silagens de milho e sorgo. Rev Bras Zootec, v.27, n.5, p.1042-1049, 1998.

RESTLE, J.; SOARES, A.B.; ROSO, C. Dinâmica de uma pastagem de aveia preta (Avena strigosa) e azevém (Lolium multiflorum) submetida a fontes de nitrogênio. In: REUNIÃO ANUAL DA
SOCIEDADE BRASILEIRA DE ZOOTECNIA, 34., 1997, Juiz de Fora. Anais... Juiz de Fora : SBZ, 1997. p.179-181.

RESTLE, J.; ROSO, C.; SOARES, A.B. Produção animal e retorno econômico em misturas de gramíneas anuais de estação fria. Rev Bras Zootec, v.28, n.2, p.235-243, 1999.

RESTLE, J. et al. Produtividade animal e retorno econômico em pastagem de aveia preta mais azevém adubada com fontes de nitrogênio em cobertura. Rev Bras Zootec, v.29, n.2, p.357-364, 2000.

ROSO, C. et al. Aveia preta, triticale e centeio em mistura com azevém. 1. Dinâmica, produção e qualidade de forragem. Rev Bras Zootec, v.29, n.1, p.75-84, 2000a.

ROSO, C. et al. Aveia preta, triticale e centeio em mistura com azevém. 2. Produtividade animal e retorno econômico. Rev Bras Zootec, v.29, n.1, p.85-93, 2000 b.

SAS. Institute Inc. SAS Language reference. Version 6. Cary, NC : SAS Institute, 1993. 1042p. 